\title{
CONCILIAÇÃO: INSTRUMENTO DE CELERIDADE E EQUILÍBRIO PROCESSUAL NA JUSTIÇA DO TRABALHO
}

\author{
https://dx.doi.org/10.48097/2674-8673.2021n5p03
}

\author{
Jonathas Ferreira da Silva Lopes ${ }^{1}$ \\ Severina Francisca Roberto da Silva ${ }^{2}$ \\ Carlos Augusto da Silva Cavalcanti ${ }^{3}$
}

\section{RESUMO}

O presente artigo foi elaborado, através de pesquisa bibliográfica, com a finalidade de elucidar o tema sobre a conciliação como uma ferramenta capaz de atuar na celeridade e equilíbrio processual na Justiça do Trabalho, tendo em vista os desdobramentos do referido tema, objetivando uma resposta legal, fundada nas Consolidações das Leis Trabalhistas de 2017 e demais autores que dispunham sobre o referido assunto. Este trabalho mostra a eficiência, eficácia e viabilidade dos instrumentos da mediação e conciliação nas relações jurídicas, a fim de solucionar o litígio na Justiça do Trabalho.

Palavras-chave: Conciliação. Mediação. Conflitos trabalhistas. Processo trabalhista.

Data de submissão: 12/02/2021

Data de aprovação: 31/03/2021

\begin{abstract}
The present article was elaborated, through bibliographic research, with the purpose of elucidating the theme about the conciliation as a tool capable of acting in the speed and procedural balance in the Labor Justice, considering the unfolding of the referred theme, aiming at a legal answer, founded on the Consolidations of the Labor Laws of 2017 and other authors who provided on the referred subject. This work shows the efficiency, effectiveness and viability of the instruments of mediation and conciliation in legal relations, in order to resolve the dispute in the Labor Court.
\end{abstract}

Keywords: Conciliation. Mediation. Labor conflicts. Labor process.

\footnotetext{
${ }^{1}$ Discente do Curso de Bacharelado em Direito da Faculdade Metropolitana da Grande Recife.

E-mail: jonathasferreira34@gmail.com

2 Discente do Curso de Bacharelado em Direito da Faculdade Metropolitana da Grande Recife.

E-mail: ninhalima21@hotmail.com

${ }^{3}$ Orientador / Docente do Curso de Bacharelado em Direito da Faculdade Metropolitana da Grande Recife.

E-mail: carloscavalcanti@metropolitan.edu.br
} 


\section{INTRODUÇÃO}

O tema em tela reveste-se de esplêndida importância para a sociedade, vez que aprimora o relacionamento das partes que litigam na Justiça do Trabalho com a finalidade de produzir, sem delongas, uma decisão justa, célere e eficaz.

Não há dúvida de que a ferramenta digital é um sinal de mudança e aperfeiçoamento na estrutura do Poder Judiciário. Sua razão de ser influenciou não só o mundo, mas também a própria seara jurídica que, durante este período de pandemia, vem inovando reiteradamente a Justiça do Trabalho.

Não obstante, durante este período pandêmico, houve significativas mudanças na Justiça do Trabalho que atingiu o arcabouço do Poder Judiciário, razão pela qual a ferramenta digital implicou na reorganização do ideal jurídico e levou os juristas a um senso mais crítico e célere, a fim de manter o exercício jurisdicional.

Tanto é que, hoje, as audiências estão sendo realizadas na modalidade telepresencial, notadamente por videoconferência, garantindo soluções equilibradas e segurança jurídica, revelando o mundo virtual como instrumento fundamental para a pacificação nas relações trabalhistas.

O princípio da conciliação é um método, obrigatório, legal, de solução consensual de conflitos, conforme o artigo $3^{\circ}, \S 3$ do Código de Processo Civil.

A conciliação é caracterizada pelas permissões mútuas, ou seja, quando ambas as partes abrem mão, de parte, de sua pretensão, com o propósito de resolver o conflito de forma mais rápida, aceitando um pouco menos do valor que tem direito.

Segundo o pensamento de Eduardo Gabriel Saad (2000), “conciliação é o ato pelo qual o juiz oferece ao reclamante e ao reclamado as bases para composição de seus interesses em conflito".

Não obstante, o pensamento de Souza (2016) ratifica que a conciliação é definida “como um processo autocompositivo breve no qual as partes ou os interessados são auxiliados por um terceiro, neutro ao conflito, ou por um painel de pessoas sem interesse na causa, para assistir a ela, por meio de técnicas adequadas, a chegar a uma solução ou a um acordo".

Contudo, este meio alternativo de resolução dos conflitos, chamado conciliação, trouxe vários aspectos positivos, externando-os ao mundo jurídico, tendo em vista o advento das leis 9.957/2000, e 9.958/2000, que deram mais importância à conciliação. (BRASIL, 2000). 


\section{A conciliação como método de solução dos conflitos trabalhistas}

A conciliação tem como método alternativo de obter solução consensual, entre as partes envolvidas, sem precisar recorrer ao judiciário.

É importante a viabilização desses mecanismos que proporcionam aos interessados essa solução de conflitos.

Vale ressaltar que, acerca do que se refere aos meios de soluções de conflitos, dentre eles a mediação, arbitragem e conciliação, podem apresentar mecanismos para a edificação de soluções de litígios, sem precisar ir ao judiciário para o ajuizamento de ações, que tem como fator predominante o alcance da pacificação social.

Segundo Souza (2016), no cenário atual, com base nas políticas públicas, no Conselho Nacional de Justiça, e consolidada nas resoluções e publicações diversas, a conciliação no âmbito do Poder Judiciário visa:

I- $\quad$ além do acordo, uma efetiva harmonização social das partes;

II- $\quad$ restaurar, dentro dos limites possíveis, a relação social das partes;

III- utilizar técnicas persuasivas, mas não impositivas ou coercitivas para se alcançarem soluções;

IV- demorar suficientemente para que os interessados compreendam que o conciliador se importa com o caso e a solução encontrada;

V- humanizar o processo de resolução de disputas;

VI- preservar a intimidade dos interessados sempre que possível;

VII- visar à solução construtiva para o conflito, com enfoque prospectivo para a relação dos envolvidos;

VIII- permitir que as partes sintam-se ouvidas; e

IX- utilizar-se de técnicas multidisciplinares para permitir que se encontrem soluções satisfatórias no menor prazo possível.

Destarte à conciliação das partes, consideram-se recorrente as demandas judiciais e a premente necessidade de solução alternativa na qual possibilite essa redução do número de demandas que afogam o judiciário.

No entanto, busca-se por métodos alternativos e consensual que sejam adequados para por fim aos conflitos, no qual se destaca a conciliação, como meio de solução dos conflitos trabalhistas.

Outrossim, conforme preconiza Schiavi (2016, p. 40), a conciliação judicial trabalhista é o meio de solução do conflito trabalhista, mediante o ingresso de concessões recíprocas. 
Por fim, o conciliador tem como função precípua a intervenção ativa na negociação das partes, à medida que se apresentam eventuais soluções para determinado conflito, razão pela qual a conciliação tem como base a autonomia privada, mesmo no que diz respeito à iniciativa como procedimento de negociação.

\section{Do princípio da indisponibilidade e da conciliação}

Segundo Delgado (2016), o princípio da indisponibilidade nos direitos trabalhistas significa a inviabilidade técnico-jurídica de poder. $\mathrm{O}$ empregado despoja-se por uma manifestação de vontade, das vantagens e proteções que lhes asseguram a ordem jurídica e o contrato.

Nessa vertente, o princípio da indisponibilidade colabora que o empregado não pode renunciar ao direito que lhe confere proteção, por sua simples manifestação de vontade, uma vez que causa o desequilíbrio de ordem econômica, social e cultural entre os sujeitos trabalhistas.

O princípio da indisponibilidade de direitos visa assegurar ao empregado os direitos e garantias de modo que não se admite que ele renuncie, em permuta de supostos benefícios que lhe são oferecidos pelo empregador.

Assim, esse princípio revela característica imprescindível nas normas trabalhistas, sendo, em sua finalidade social, no qual o caráter protetivo reflete o interesse público, vindo a restringir os direitos das partes nas negociações trabalhistas, visando resguardar os direitos do trabalhador.

No momento em que é realizada a conciliação nas ações trabalhistas, tanto o empregado quanto o empregador sentem-se obrigados a renunciarem parte dos seus direitos para vê-los atendidos, no mínimo parcialmente, em virtude da premente necessidade em que se encontram quando recorrem ao judiciário para solução dos litígios.

Por exemplo, nas vezes em que as verbas salariais discutidas em ações trabalhistas têm cunho alimentício, consequentemente, a renúncia aos direitos assegurados pela lei aos trabalhadores configura o então chamado princípio da indisponibilidade de direitos.

No entanto, as ações trabalhistas poderão ser submetidas à conciliação a qualquer tempo processual, no intuito de garantir uma solução pacífica e justa às partes envolvidas na demanda judicial como se denota ao trabalhador parte hipossuficiente da relação trabalhista, conforme preconiza o art. 764, parágrafo $1^{\circ}$, da CLT. 


\section{A conciliação como equilíbrio das partes no processo do trabalho}

Segundo preconiza a CLT, a conciliação torna-se obrigatória em dois momentos processuais: após a abertura da audiência de instrução e julgamento, conforme o artigo 846; e depois de aduzidas as razões finais pelas partes, corroborando com o art. 850, do mesmo diploma legal, sendo certo que a sua omissão pode gerar a nulidade do julgamento.

$\mathrm{Na}$ justiça do trabalho o acordo tem prioridade absoluta. Conforme exposto na lei 9.957/2000, o procedimento sumaríssimo deu importância à conciliação. Ao dispor de aberta a sessão, o juiz esclarecerá às partes ali presentes sobre as principais vantagens da conciliação e usará os meios necessários de persuasão para a solução conciliatória do conflito em qualquer fase da audiência.

Não obstante, na lei 9.958/2000, a conciliação prévia deu o primeiro passo a fim de condicionar a tentativa de conciliação prévia no ajuizamento da ação trabalhista, conforme demonstrado no art. 625-D, em que fica claro sobre qualquer demanda de natureza trabalhista ser submetida à Comissão de Conciliação Prévia, se na localidade da prestação de serviços houver sido instituído a comissão no âmbito da empresa ou do sindicato da categoria.

Essa atitude posta e acordada perante as comissões de conciliação não possui efeito de decisão irrecorrível, razão pela qual sempre acontece com os acordos homologados pela justiça do trabalho.

A conciliação, ao decorrer do litígio trabalhista, ganha eficácia e produz efeitos jurídicos após a efetiva homologação dada pelo magistrado do trabalho.

E se houver fraude na conciliação? Caso exista, o juiz constatará que há hipótese de fraude na conciliação ou acordo manifestamente lesivo, e deverá abster-se de homologar o referido acordo, tendo em vista o exemplo de, nos casos das lides simuladas, em que o patrão estimula seus empregados a ajuizarem ações, com o exposto de celebrar acordos em valores ínfimos àqueles que de fato seriam objeto do acerto rescisório.

Entretanto, depois de obtida a chancela judicial, o acordo ganharia o status de coisa julgada, e que impediria o empregado de reclamar as diferenças devidas, razão pela qual essa situação só seria agravada quando o acordo concluísse pela quitação do objeto do pedido e extinto o contrato de trabalho. Por fim, resultaria na impossibilidade da parte pleitear em juízo qualquer direito trabalhista adquirido no curso do contrato.

No mais, a conciliação trabalhista deve ser incentivada na fase de sua importância antecipatória de prestação jurisdicional, motivo pelo qual a sua homologação, também, tem o 
dever de ser condicionada à análise do juiz, que, no entanto, deverá rejeitar sempre que detectar práticas fraudulentas ou lesivas aos interesses do trabalhador.

\section{Mediação e conciliação na justiça do trabalho durante a pandemia}

É necessário pontuarmos que o art. $3^{\circ}, \S 3^{\circ}$, do CPC/2015, é explícito ao falar sobre a conciliação e a mediação como métodos de solução consensual de conflitos.

Além do mais, o art. 846 da CLT vislumbra a necessidade e obrigatoriedade do juiz, no início da audiência, propor a conciliação. No mesmo sentido, o art. 852-E da CLT elucida que o juiz esclarecerá as partes presentes sobre as vantagens da conciliação e usará os meios adequados de persuasão para a solução conciliatória do litígio.

Caso esta não ocorra, novamente, após as partes aduzirem razões finais, a conciliação voltará a ser proposta antes da decisão judicial. É o que está expresso no art. 850 da CLT.

Ainda sobre o conceito de mediação, Dale (2016) diz que é um dos instrumentos de pacificação de natureza autocompositiva e voluntária, no qual um terceiro, imparcial, atua, de forma ativa ou passiva, como facilitador do processo de retomada do diálogo entre as partes, antes ou depois de instaurado o conflito.

Segundo a publicação de Basílio (2020), no que concerne à mediação e à conciliação durante este período pandêmico, não há como questionar que o novo coronavírus trouxe graves repercussões em todo o cenário atual, em todos os segmentos da sociedade.

Esses reflexos alcançaram, com grande avanço, a esfera jurídica de milhares de brasileiros, de tantos conflitos que surgiram ao longo de todo esse caminho e que vem sendo objeto de decisões judiciais. Como exemplo, podemos fazer menção à questão relativa ao pagamento de aluguéis, descumprimentos contratuais, embates de natureza trabalhista, rescisão de negócios jurídicos, entre outros conflitos gerados pela pandemia.

Assim, podemos observar que há um número expressivo de leis, medidas provisórias e decretos que têm como fator crucial o objeto regular, de maneira específica, nas relações sociais diante desse momento de crise econômica, social e até mesmo de saúde pública, que surgiu nessa conjuntura atual.

Por conseguinte, é possível que, porventura, milhões de demandas jurídicas venham a ser propostas, visto que dizem respeito aos litígios que decorrem da pandemia perante o Poder Judiciário. 
Vale frisar que há uma avalanche de processos judiciais aguardando o período póspandemia o que, provavelmente, será bem maior daquelas decorrentes no passado, de planos econômicos que até o presente momento transitam pelos tribunais.

Além do mais, essa eficiência e agilidade que toda população almeja para a solução dos seus conflitos ou interesses, dificilmente serão rápidos por meio das ações judiciais, tendo em vista que a demanda de tempo é maior.

Posto isto, de forma válida e eficaz, os litigantes possuem instrumentos e meios jurídicos que já vinham se destacando há um tempo no ambiente jurídico brasileiro.

Não obstante, esses instrumentos ou formas alternativas de solução de conflitos, como a conciliação e a mediação, são de baixo custo e de grande rapidez, sendo fáceis de serem realizados por meio digitais como a internet, chamada via WhatsApp, videoconferência, etc. É uma oportunidade de grande valor para a advocacia desempenhar o seu papel constitucional, além de atender às demandas jurídicas durante essa pandemia, sem precisar violar o isolamento social decretado pelos governantes.

Contudo, por meio desses instrumentos de mediação e da conciliação, que visam solucionar as disputas, também serão negociadas soluções para as ações judiciais que já vinham em curso, até mesmo antes da pandemia, portanto, essas inovações, criatividades e flexibilidades obrigaram e levaram a todos, quem quer que seja, a um senso de adaptabilidade.

A mediação e a conciliação, diante do cenário atual pandêmico, alcançaram várias transformações na seara trabalhista. Hoje, o mundo não é mais o mesmo. As versões ultrapassadas estão sendo policiadas através do mundo digital.

Em meio a este período catastrófico, várias medidas foram e estão sendo tomadas, com o propósito de continuar o exercício pleno das atividades jurídicas. Decisões judiciais, sentenças, acordos e homologações estão explicitamente detidos no âmbito do mundo virtual, por intermédio de chamadas de videoconferência.

O instrumento digital abarca ainda mais a relevância dos atos praticados na mediação e conciliação na justiça do trabalho diante da solução de conflitos.

Consoante ao entendimento do juiz federal do trabalho, coordenador da Escola Judicial do TRT do Paraná, mestre em Resolução de Disputas pela Pepperdine University (EUA) e em Direito pela UFPR, Fernando Hoffmann, a questão é promover a mediação e a conciliação de conflitos que tratem sobre a preservação da saúde e da segurança do trabalho em serviços públicos e atividades consideradas essenciais que estão descritas no art. $3^{\circ}$ do decreto $n^{\circ}$. 10.282/2020, que busca privilegiar soluções que não venham a inviabilizar a continuidade. 
$\mathrm{O}$ ato na mediação e conciliação dar-se-á nos conflitos individuais e coletivos em âmbito pré-processual. Evidencia-se que esses conflitos listam-se aos interesses do exercício de atividades laborais e do funcionamento das atividades empresariais, que diz respeito ao contexto da situação excepcional da pandemia.

Uma grande inovação é que a Justiça do Trabalho tradicional exercia as atividades apenas na mediação pré-processual de conflitos coletivos.

Necessário pontuar que sobre os dissídios individuais, a Justiça do Trabalho não considera a mediação pré-processual adequada pelo fato de não possuir lide, isto é, o conflito de interesses entre o empregador e o empregado. Em razão do acordo de interesses, não foi dado aos juízes mediarem em processo que não aborda um conflito.

No mais, a adequada e oportuna recomendação inova a sistemática, desde que contemple os dissídios individuais específicos e que sejam recorrentes na sua atualidade, que decorrem de conflitos entre o empregado e empregador, que envolve a preservação da saúde e da segurança do trabalho em serviços públicos e a continuidade das atividades consideradas essenciais.

Essas diretrizes expostas são excepcionais e voltadas à mediação e à conciliação, por meios eletrônicos e por videoconferência de conflitos individuais e coletivos, anteriormente à fase processual, à proporção que perdurar o período de pandemia.

Não obstante, as recomendações aos juízes do trabalho, em geral, destinam-se para todos os magistrados, plantonistas e, principalmente, aos integrantes dos Núcleos Permanentes de Métodos Consensuais de Solução de Disputas (NUPEMECs-JT) e dos Centros Judiciários de Métodos Consensuais de Solução de Disputas (CEJUSCs-JT), sendo ele de $1^{\circ}$ e $2^{\circ}$ graus.

Contudo, desde que respeitado o livre convencimento e a independência funcional dos juízes, o ato recomenda a realização de esforços, a fim de fazer acontecer a mediação e a conciliação de conflitos que trata sobre a preservação da saúde e posterior segurança do trabalho em serviços públicos. As atividades essenciais deverão ser em busca de soluções que não venham dificultar a continuidade da prestação de serviço, todavia, o ato destaca a necessidade da participação e interação das partes envolvidas no processo.

Vale ressaltar que os magistrados devem sempre atuar com o apoio direto das entidades sindicais, dos advogados e dos membros do Ministério Público do Trabalho.

Além do mais, até a efetiva execução de ferramenta nacional unificada para adotar e adequar à mediação e à conciliação, os magistrados do trabalho devem ficar atentos, especificamente, na utilização de aplicativos ou programas de mensagens e por 
videoconferência de acesso público e gratuito, visto que sejam dotados de funcionalidades de gravação de mídia audiovisual, para assim poder ficar preservado na memória das tratativas e da documentação da homologação dos acordos.

Destarte, o potencial da mediação e conciliação durante e pós-pandemia demonstra ser consenso geral e de caráter importantíssimo e, posteriormente, essa fase ser superada, a parte principal de combate à pandemia, caso possua esforço a fim de transfigurar a conjuntura pandêmica em circunstância favorável, o Poder Judiciário do Trabalho poderá sair melhor que antes da crise.

No entanto, existem conflitos trabalhistas que são negociáveis e mediáveis a cunho privado, no que garante as condições de equilíbrio de poder entre as partes.

Esses conflitos, que são mediáveis, de forma pré-processual ou extraprocessual, judicialmente conciliáveis, entende-se ser necessária a assistência de um terceiro e o magistrado será o mediador.

Em epítome, a conciliação judicial é denominada como uma espécie de mediação a ser conduzida pelos juízes do trabalho, no trâmite do dissídio trabalhista. Portanto, as técnicas de conciliação são mais limitadas ao invés da mediação genérica, e que por vezes, tendo uma solução negociada, somente será atingida após o processo de judicialização. Razão pela qual, nos casos em que não seja possível a negociação, em função do relacionamento entre as partes litigantes, da condição socioeconômica e da natureza do interesse a ser tutelado, (pré) mediáveis e conciliáveis, a Justiça do Trabalho deverá focar os esforços com a finalidade de culminar os conflitos por intermédio de decisão vinculante.

\section{CONSIDERAÇÕES FINAIS}

Em virtude de sua viabilidade e execução na seara jurídica trabalhista e nas demais relações de trabalho, bem como o teor de sua importância no equilíbrio entre as partes que litigam junto à Justiça do Trabalho, intencionando o aperfeiçoamento e/ou a compreensibilidade do diálogo entre o empregado e o empregador, o tema traz consigo um marco precípuo, objetivando o respeito constitucional ao princípio do devido processo legal e a sua eficácia, a fim de vincular à égide a parte mais fraca na relação processual.

Não obstante, durante este período pandêmico, houve significativas mudanças na Justiça do Trabalho que atingiu o arcabouço do Poder Judiciário, motivo este, que a ferramenta digital implicou na reorganização do ideal jurídico, levando a um senso mais crítico e célere, com o intuito de manter o exercício jurisdicional. 
As audiências na Justiça do Trabalho estão sendo realizadas na modalidade telepresencial, notadamente por videoconferência, garantindo soluções equilibradas e a segurança jurídica no decorrer do processo, revelando o mundo virtual como instrumento fundamental para pacificação nas relações trabalhistas.

Todavia, em meio ao cenário de pandemia, que está reestruturando a seara jurídica, seja ela trabalhista ou não, em nível mundial, o instrumento digital ganhou voz, vez, espaço e oportunidade que cada vez soa fortemente, levando à consciência dos legisladores e juristas, um meio e soluções eficazes, com o propósito de inovar o arcabouço do Poder Judiciário nas relações sociais, isto é, os meios digitais revelaram ao mundo jurídico resoluções que já existiam, mas não eram valoradas significativamente da forma que é hodiernamente.

\section{REFERÊNCIAS}

BASÍLIO, Ana Tereza. A mediação e a conciliação em tempos de pandemia. Jornal do Brasil, publicado em 20 de Maio de 2020. Disponível em: https://www.jb.com.br/pais/artigo/2020/05/1023840-a-mediacao-e-a-conciliacao-em-temposde-pandemia.html. Acesso em: 08 dez. 2020.

BRASIL. Lei $\mathrm{n}^{\mathrm{o}}$ 13.467, de 13 de julho de 2017. Reforma Trabalhista. Altera a Consolidação das Leis do Trabalho (CLT), aprovada pelo Decreto-Lei $\mathrm{n}^{\circ} 5.452$, de $1^{\circ}$ de maio de 1943, e as Leis $\mathrm{n}^{\circ}$ 6.019, de 3 de janeiro de 1974, 8.036, de 11 de maio de 1990, e 8.212, de 24 de julho de 1991.

COSTA, Paulo Roberto Sifuentes. A conciliação no processo do trabalho. TRT da $3^{\mathrm{a}}$ Região. http://www.stf.jus.br/arquivo/cms/conciliarConteudoTextual/anexo/A_conciliacao_no_proces so_do_trabalho.pdf. Acesso em: 08 maio 2020.

DALE, Izadora Farias Freitas Azeredo. A mediação: conceito, princípios norteadores e técnicas para sua aplicabilidade. Disponível em: https://jus.com.br/artigos/48697/amediacao-conceito-principios-norteadores-e-tecnicas-para-sua-aplicabilidade\#_ftnref6.

Acesso em: 10 dez. 2020.

DELGADO, Mauricio Godinho. Curso de direito do trabalho. 15. ed. São Paulo: LTr, 2016.

HOFFMANN, Fernando. Mediação e Conciliação na Justiça do Trabalho Durante A Pandemia. Revista Consultor Jurídico, 21 de abril de 2020. Disponível em: https://www.conjur.com.br/2020-abr-21/hoffmann-mediacao-conciliacao-justica-trabalho. Acesso em: 02 out. 2020.

SAAD, Eduardo Gabriel. Comissões de conciliação prévia. São Paulo: LTr, 2000. 
SCHIAVI, Mauro. Manual de direito processual do trabalho. 10 ed. De acordo com o novo CPC. São Paulo: LTr, 2016.

SOUZA, Aiston Henrique et al. Manual de Mediação Judicial. Conselho Nacional de Justiça. 6. ed. Brasília-DF: 2016.

VELOSO, Cynara S. M.; SANTOS, Cássia Cruz; OTONI, Arthur F. B. B.; LIMA, Géssica D. S. Conciliação na justiça do trabalho. Publicado em 07/2018. Disponível em: https://jus.com.br/amp/artigos/67894/1. Acesso em: 08 maio 2020. 